\title{
An application system for the design of the spindle tool clamping mechanism
}

\author{
Parthiban Kannan', Ragul Ramanathan² \\ ${ }^{1}$ Schneider Electric Private Limited, Global Technology Center, Bengaluru, India \\ ${ }^{2}$ Technical University Bergakademie Freiberg, Institute of Iron and Steel Technology, Freiberg, Germany
}

\section{Article Info \\ Article history: \\ Received Oct 10, 2020 \\ Revised Apr 9, 2021 \\ Accepted May 27, 2021 \\ Keywords: \\ CNC machine \\ Disc spring \\ Machining center design \\ Spindle \\ Tool clamping system}

\begin{abstract}
The heart of the machining center design is the spindle design, and one of the primary functions in the spindle design is a tool clamping system mechanism. The selection of disc spring stack for a tool clamping mechanism is an iterative process that highly depends on the spindle space availability, drawbar design, tool unclamp stroke length, and standard clamping force requirements. For example, even a design space of $0.1 \mathrm{~mm}$ may impact one $\mathrm{kN}$ clamping force depending on the disc spring stack design. Hence the design of the tool clamping system for a spindle is a timeintensive process and also needed careful attention. The iterative process of disc spring stack selection may lead to an unoptimized tool clamping system, which may not be the best design. This paper explains a dynamic way to find the best spring stack selection to optimize the spindle tool clamping mechanism based on the computational application.
\end{abstract}

This is an open access article under the CC BY-SA license.

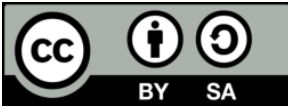

\section{Corresponding Author:}

Parthiban Kannan

Schneider Electric Private Limited

Global Technology Center

Tower-C, 63/3B, Whitefield Ashram road, Hobli, Bidarahalli, Gorvigere Village, Bengaluru, Karnataka

560067, India

Email: parthiban_kannan@outlook.com

\section{NOMENCLATURE}

$C_{f}$ Tool clamping force

$D_{d}$ Drawbar outer diameter

$D_{e} \quad$ Disc spring outer diameter

$D_{i} \quad$ Disc spring inner diameter

$D_{s} \quad$ Spindle inside diameter

$F \quad$ Spring force of a single spring

$F_{p} \quad$ Preloaded Force of a spring stack

$F_{s} \quad$ Spring force of a spring stack

$F_{t} \quad$ Tool unclamp cylinder thrust force

$F_{u} \quad$ Tool unclamp force

$i \quad$ Number of springs (or) spring sets in series

Id $\quad$ Spindle inner diameter

$\begin{array}{rllr}N & L_{\mathrm{O}} & \text { Unloaded or Free Stack Length of spring stack } & \mathrm{mm} \\ \mathrm{mm} & l_{\mathrm{O}} & \text { Height of a single unloaded spring } & \mathrm{mm} \\ \mathrm{mm} & L_{p} & \text { Spindle stack preload length } & \mathrm{mm} \\ \mathrm{mm} & L_{s} & \text { Deflection of a spring stack } & \mathrm{mm} \\ \mathrm{mm} & L_{u} & \text { Tool unclamp length (or) Tool release length } & \mathrm{mm} \\ N & n & \text { Number of parallel springs in a set } & \mathrm{Nos} \\ N & P_{\%} & \text { Preloaded percentage of a spring stack } & \% \\ N & P_{d} & \text { Preloaded deflection of a spring stack } & \mathrm{mm} \\ N & t & \text { Thickness of a disc spring } & \mathrm{mm} \\ N & U_{\%} & \text { Unclamp load percentage of a spring stack } & \% \\ \text { Nos. } & U_{d} & \text { Tool unclamp deflection of a spring stack } & \mathrm{mm}\end{array}$

\section{INTRODUCTION}

A machining center spindle has a tool to remove the material from the workpiece in the machining process. Since different kinds of machining operations may require various tools, the tool is detachable from 
the spindle. Hence tool clamping system is designed to hold the tool against the force applied during the machining operations [1], [2].

Zhu et al. [3] described, a tool clamping system uses the preloaded disc springs with a combination of parallel and the series arrangement inside the spindle stack length to hold the tool. The preload on the springs in the tool clamped condition decides the actual pulling force of the tool. The clamping force requirements may vary from the tool taper manufacturing standards. Also, while exchanging the tool from the Automatic tool changer, the tool has to be released from the spindle. An axial thrust cylinder-piston mechanism used to provide a significant thrust to the drawbar, which compressing the disc spring stack to release the tool through a collet mechanism [4], [5].

Disc springs selection and its arrangement in the tool clamping system may depend on the following factors.

a. Tool clamping force $\left(C_{f}\right)$

Figure 1 shows the clamping system of the spindle tool.

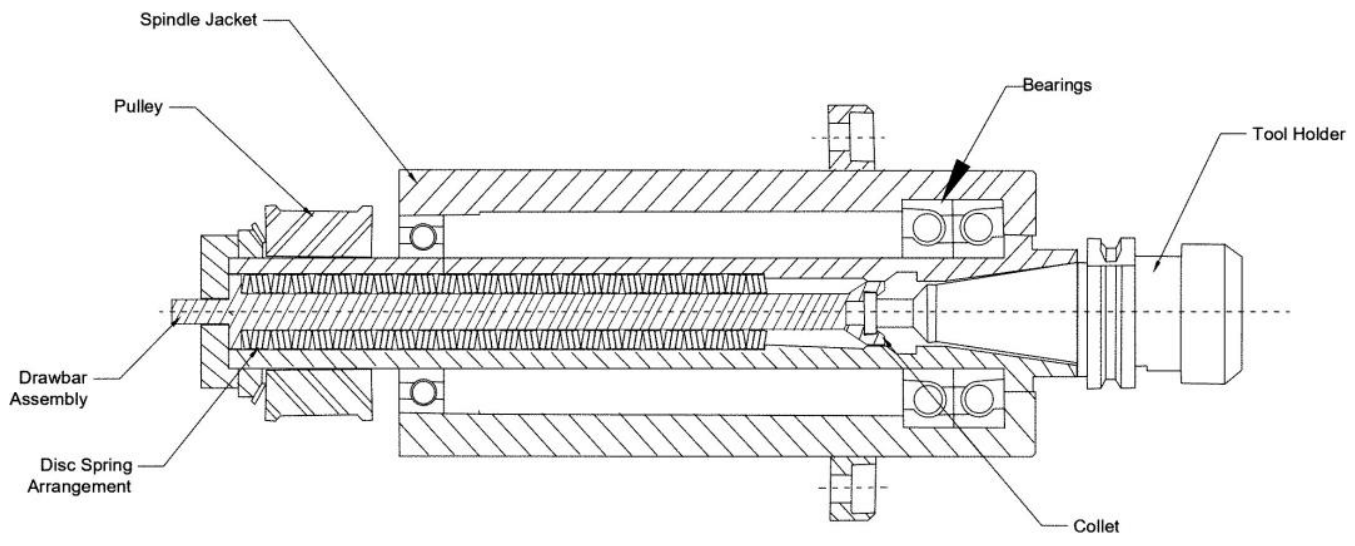

Figure 1. Spindle tool clamping system

b. Spindle inside diameter (Ds)

c. Spindle stack length (Lp)

d. Drawbar outside diameter (Dd)

e. The drawbar axial movement to release the tool $(\mathrm{Lu})$

However, the selection of spring stack, drawbar length and outside diameter, spindle stack length and inside diameter, thrust cylinder stroke length and thrust load capacity, and spindle taper clamping force are highly correlated. It makes the system more complicated and needs an iterative process to design the optimized tool clamping system. Hence the design process is time-intensive, and also, careful attention is required since even small dimension change can affect the tonne of the clamping force, which possible to make the complete system failure. Hence, a strong need exists in the machine tool industries for a system or method that can givedynamic and instant solutions to the tool clamping system design while disc spring stack selection.

This paper explains the method of developing such a system for tool clamping mechanism design. A machine tool designer with the necessary software development skills described in [6] can develop thissystem by referring to this paper. Otherwise, they can collaborate with computer engineer to develop it.

\section{SYSTEM DESIGN}

Industries can choose their application development platform based on the license's availability or choose from any open-source platforms. Build a computation system using an integrated development environment (IDE) [7], [8]. Visual studio code, Eclipse, and NetBeans are some of the well developed opensource IDE available in the market. IDE links the front-end and back-end language to compile and build the application. Programming languages are used to simulate the conceptual ideas on a real machinedescribed in [9], [10]. Implement the computational methods using back-end programming language supported by the IDE. C sharp, Java, Python are some of the standard back-end programs. Design a front-end system interface for man-computer system interaction [11] to receive the tool clamping system's design parameters from the designers. XAML, XML, and HTML are some of the markup languages used to design system interfaces. 
The system identifies disc spring selection and possible spring stack to the designers based on the input received. The user needs to feed the spindle design and tool clamping system parameters as the system input. Figure 2 and Figure 3 illustrate the application system design required to receive the designer inputs:
a. Tool clamp parameters
b. Tool unclamp parameters
c. Advanced control

\subsection{Tool clamp parameters}

The tool clamping parameters contain spindle inside diameter $\left(D_{s}\right)$ to decide the maximum diameter of the disc spring $\left(D_{e}\right)$, drawbar outside diameter $\left(D_{d}\right)$ to select the minimum diameter of the disc spring $\left(D_{i}\right)$. Spindle stack preload length $\left(L_{p}\right)$, and tool clamping force $\left(C_{f}\right)$ are to determine the spring stack arrangement.

Decimal input required for spindle inside diameter, drawbar outer diameter, and the spindle stack preload length. Provide drop-down to choose tool clamping force $\left(C_{f}\right)$ from the taper standards. Work by Bossmanns and Tu [13] explained Tool clamping force varies from the tool taper standards and size of the tool taper so industries can decide their standards required in the application. Table 1 depicts ISO standard clampingforces for reference.

Table 1. Standard clamping forces per [12]

\begin{tabular}{lc}
\hline Taper size & Clamping force $\left(\mathrm{C}_{\mathrm{f}}\right)$ \\
\hline HSK - A/C 32 & $5000 \mathrm{~N}$ \\
HSK - A/C 40 & $6800 \mathrm{~N}$ \\
HSK - A/C 50 & $11000 \mathrm{~N}$ \\
HSK - A/C 63 & $18000 \mathrm{~N}$ \\
\hline
\end{tabular}

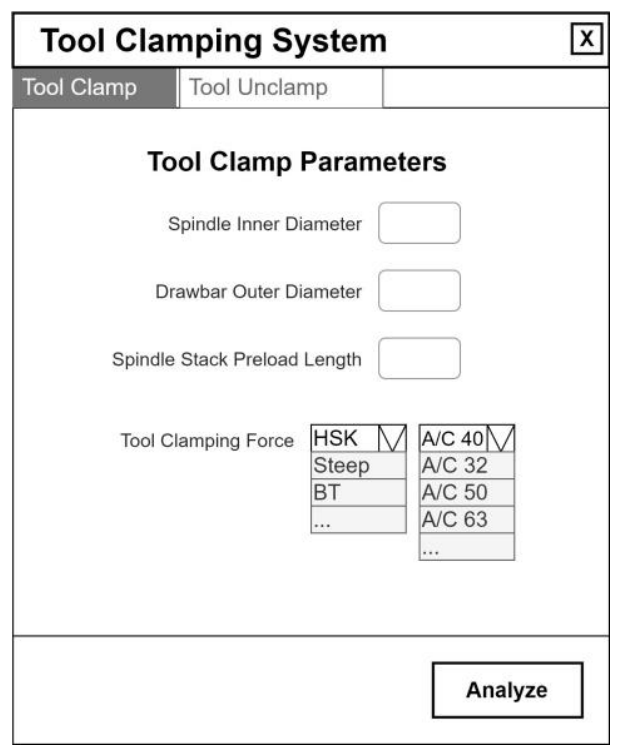

Figure 2. Spindle tool clamping system

\subsection{Tool unclamp parameters}

The tool release parameters comprise the tool release stroke length and cylinder thrust force $\left(F_{t}\right)$ to decide the force requirement $\left(F_{u}\right)$ of the disc spring stack arrangement to release the tool. Both tool release stroke length and the cylinder thrust force [14] should be the decimal input.

\subsection{Advanced control}

The application needs some advanced control to set the system unit [15] and to control the spring stack. The designer can set the maximum number of springs in parallel and the maximum number of series to control the stack arrangement. These two inputs should be in the integer form. Provide a drop-down option to select the required system of the unit for complete operation. It may vary depends on the industries and countries. 


\section{SYSTEM DATABASE}

A system database is used to store and manipulate a large amount of data for computational purposes [16]. Prepare a disc spring database to connect with the computational system. Developers can use any Excel, MS Access, or SQL servers database, depending on the development requirement. Collect the data from the disc spring supplier catalog [4], [5]. Table 2 depicts the database design to store disc spring data.

Table 2. Reference for disc spring database design

\begin{tabular}{llllllll}
\hline ID & Manufacturer & Reference & Outer Diameter $\left(D_{e}\right)$ & Inner Diameter $\left(D_{i}\right)$ & Thickness $(t)$ & Height $\left(l_{0}\right)$ & Force $(F)$ \\
\hline 01 & Schnorr & 017308 & 50.0 & 25.40 & 1.50 & 3.10 & 2842 \\
02 & Schnorr & $014600 \mathrm{~B}$ & 50.00 & 25.40 & 2.0 & 3.40 & 5895 \\
03 & Mubea & 180040 & 50.00 & 18.4 & 1.25 & 2.75 & 1368 \\
\hline
\end{tabular}

The ID is the unique identifier number of each spring. Add the manufacturer name to distinguish the multiple suppliers. The supplier reference is the reference number given by the supplier. Add the disc spring's basic dimensions such as outer diameter $\left(D_{e}\right)$, inner diameter $\left(D_{i}\right)$, thickness $(t)$, and height of a disc spring (10). Force $(\mathrm{F})$ is the total force required to flat a single spring. The disc spring force can be calculated from DIN 2092 [17] guidelines.

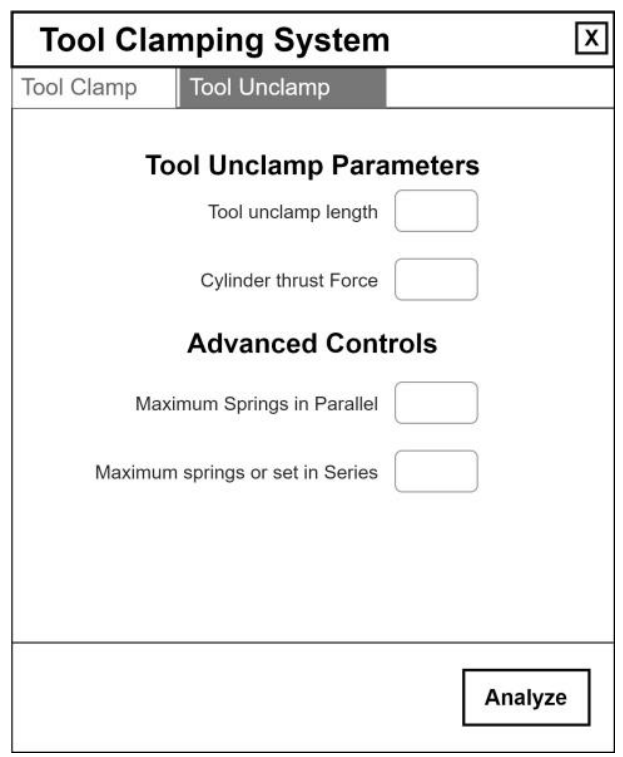

Figure 3. Spindle tool clamping system

\section{WORKING PRINCIPLE}

The system's main objective is to calculate the forces and stack length of disc spring stack on tool clamp and unclamp conditions to optimize the tool clamping system design. Figure 4 illustrates the disc spring positions at tool clamp and unclamp conditions. During preloaded or tool clamp conditions, the spring stack is compressed inside the spindle using a drawbar locked with an end cap. While tool unclamps condition, the tool unclamp cylinder further pushes the drawbar inside to release the tool. Hence the spring stack further compressed. The method to find the possible spring stacks to achieve these both conditions illustrated as a flowchart in Figure 5. 

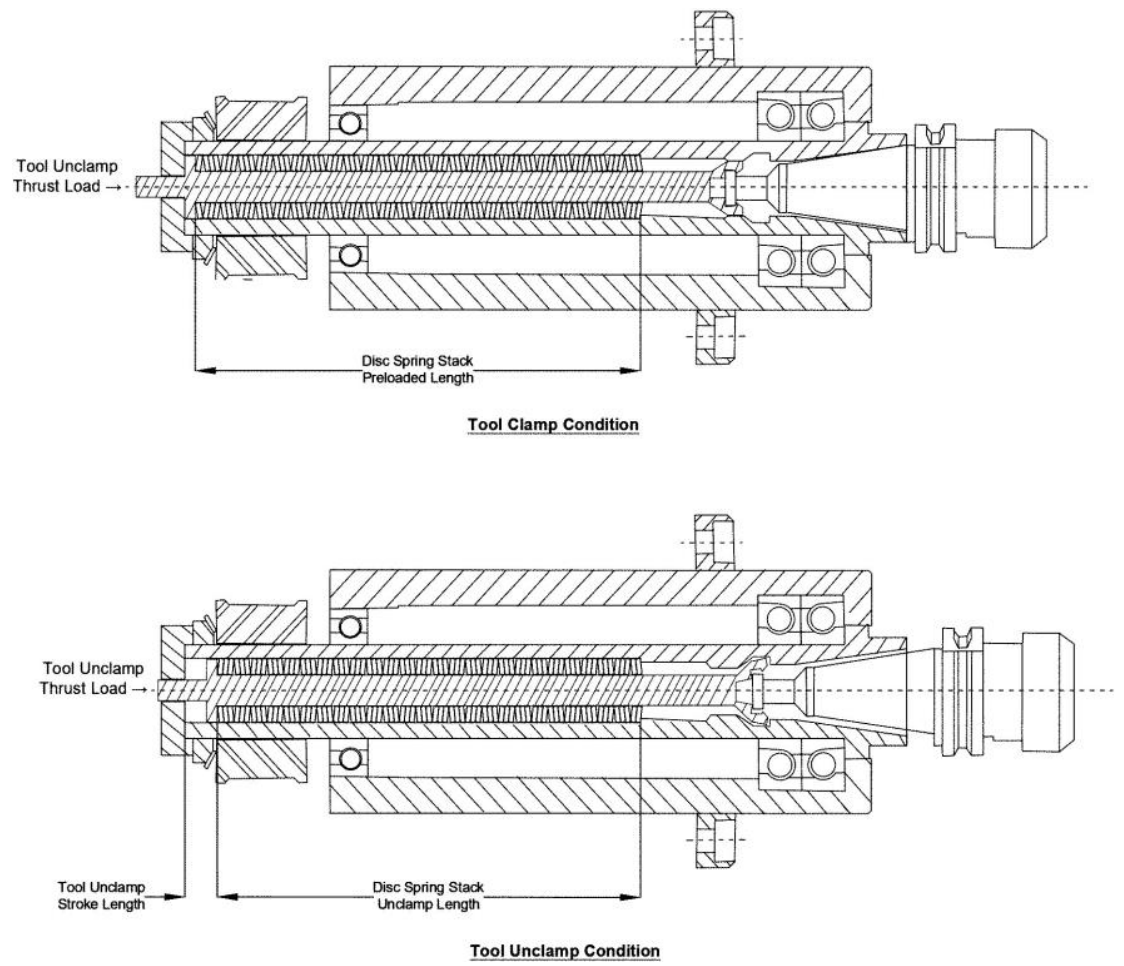

Figure 4. Tool clamp and unclamp conditions

a. Filter the spring data from the database, see Table 2. The filter selects the disc spring outer $\left(D_{e}\right)$ diameter lesser than the spindle inside diameter $\left(D_{s}\right)$ and the disc spring inner diameter $\left(D_{i}\right)$ higher than the drawbar outside diameter $\left(D_{d}\right)$ as showing Table 3. Add the disc spring diameter clearance while considering diameter [17].

Table 3. Clearance between guide and disc spring diameters $\left(D_{e} \& D_{i}\right)[17]$

\begin{tabular}{cc}
\hline$D_{e} \& D_{i}$ & Clearance to $16 \mathrm{~mm}$ \\
\hline over 16 to $20 \mathrm{~mm}$ & $0.3 \mathrm{~mm}$ \\
over 20 to $26 \mathrm{~mm}$ & $0.4 \mathrm{~mm}$ \\
over 26 to $31.5 \mathrm{~mm}$ & $0.5 \mathrm{~mm}$ \\
over 31.5 to $50 \mathrm{~mm}$ & $0.6 \mathrm{~mm}$ \\
over 50 to $80 \mathrm{~mm}$ & $0.8 \mathrm{~mm}$ \\
over 80 to $140 \mathrm{~mm}$ & $1.0 \mathrm{~mm}$ \\
over 140 to $250 \mathrm{~mm}$ & $1.6 \mathrm{~mm}$ \\
$D_{e} \& D_{i}$ & Clearance to $16 \mathrm{~mm}$ \\
\hline
\end{tabular}

b. Limit the disc springs stack to the process by the number of springs in parallel (n) and series (i) value from the advanced controls input, see Figure 3.

c. Start the disc spring stack from one spring in parallel $(n=1)$ and one spring in series (i=1). Figure 6 illustrates the various spring stack arrangement for reference.

d. Calculate free stack length (L0) for the disc springs filtered from the database [17], [18].

$$
\mathrm{L}_{0}=\mathrm{i}\left(\mathrm{l}_{0}+(\mathrm{n}-1) \cdot \mathrm{t}\right)
$$

Where $i$ is the number of springs in series, $l_{0}$ is the height of unloaded single spring, $n$ is the number of springs in parallel, and $t$ is the spring's thickness.

e. Calculate the preloaded disc spring force $(\mathrm{Fp})$.

$$
\mathrm{F}_{\mathrm{p}}=\mathrm{F}_{\mathrm{s}} \cdot \mathrm{F}_{\%}
$$


Where $F_{s}$ is the spring force of a spring stand, and $P_{\%}$ is the preloaded percentage of a spring stack.

$$
F_{s}=n \cdot F
$$

Where $F$ is the force required to flat a spring [17].

$$
P_{\%}=\left(\frac{P_{d}}{L_{s}}\right) \cdot 100
$$
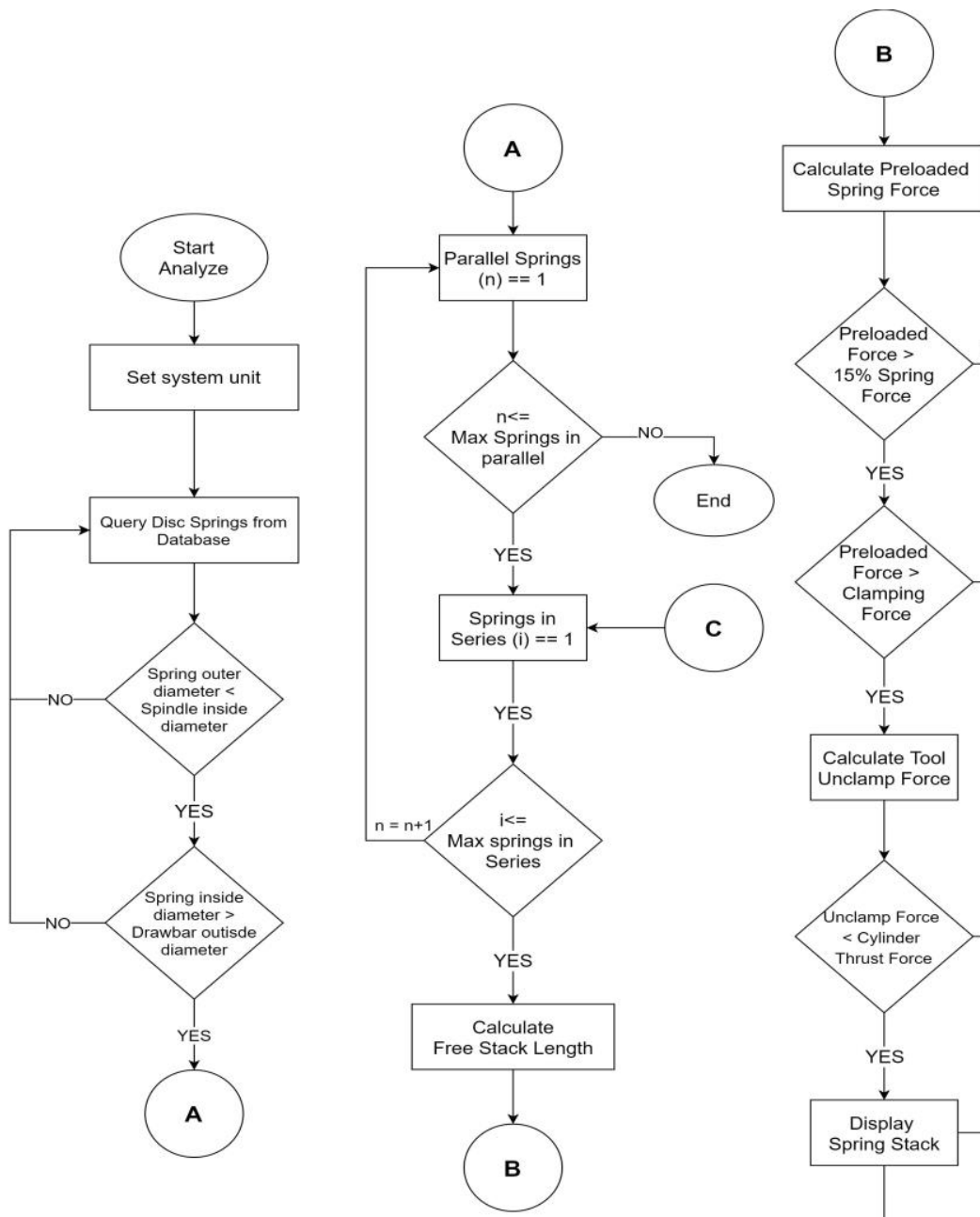

Spring Force
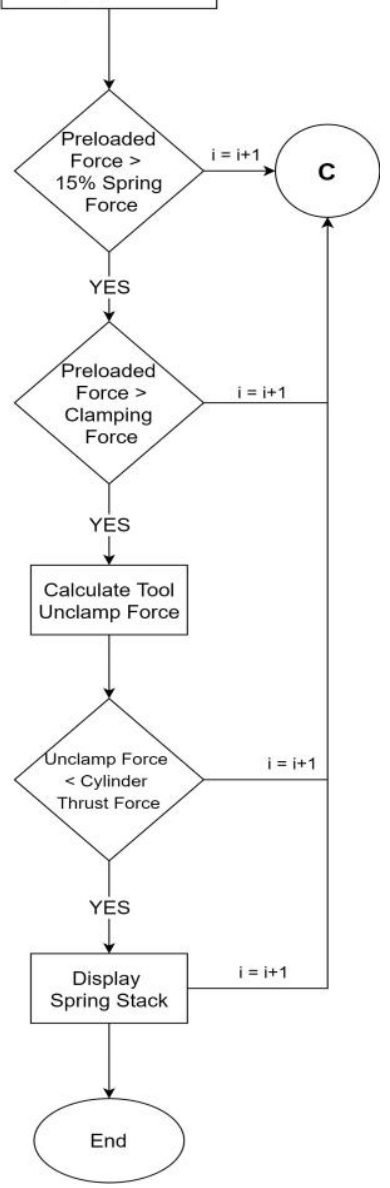

Figure 5. Working principles

Where $P_{d}$ is preloaded deflection of a spring stack and $L_{s}$ is deflection of a spring stack.

$$
P_{d}=L_{0}-L_{p}
$$

Where $L p$ is spindle stack preloaded length

$$
L_{s}=i .\left(l_{0}-t\right)
$$

f. The springs preloaded with a minimum of $15 \%$ of the spring force of a spring stack $\left(F_{s}\right)$ to avoid compression tension alternating stresses [18]. Hence ignore the spring stacks where the preload force $\left(F_{p}\right)$ is less than that. 
g. Calculate the tool unclamp force $(\mathrm{Fu})$.

$$
F_{u}=F_{s} \cdot U_{\%}
$$

Where $F_{s}$ is spring force of a spring stack, and $U_{\%}$ is unclamping load percentage of a spring stack.

$$
U_{\%}=\left(\frac{U_{d}}{D_{s}}\right) \cdot 100
$$

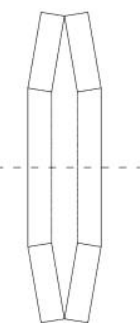

Series - 2 Parallel - 1

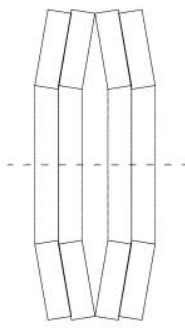

Series - 2 set Parallel - 2

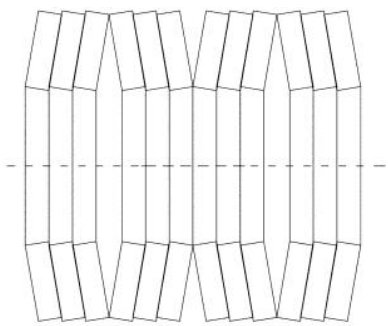

Series - 4 set Parallel - 3

Figure 6. Disc spring stacks-reference

Where $U_{d}$ is tool unclamp deflection of a spring stack.

$$
U d=L_{0}-L_{u}
$$

Where $L_{u}$ is tool unclamp or tool release length.

h. The Tool unclamp force (Uf) should be lesser than $80 \%$ of the spring force (Fs) of the spring stack [18]. Hence ignore the stacks where the tool unclamp force is higher than that.

i. Also, ignore the Tool unclamp force (Uf) higher than the Tool unclamp cylinder thrust force (Ft).

j. Display the disc spring stack to the user and do the operation for all the stack combination.

\section{RESULTS AND DISCUSSION}

From Kleinberg studies [19], once the algorithm processed all the springs in the database for the given tool clamp mechanism parameters, it filters the suitable springs stacks. A front-end system is designed to display the list of filtered springs. The output list may contain one or more spring stacks depends on the clamping mechanism requirement. Jacob [20] proposed the User Interface clearly defined with required parameters.

- $\quad$ Spring reference number to identify the manufacturer details from the database

- $\quad$ Spring dimensions $\left(D_{e}, D_{i}, \mathrm{t}, l_{0}, \mathrm{i}\right)$ and stack information (i, n, Total) for design reference

- $\quad$ Spring stack length $\left(L_{0}\right)$ and forces $\left(F_{p}, F_{u}\right)$ for further work on design of spindle and tool clamp cylinder

Figure 7 illustrates the reference system design to show feasible disc spring stacks. Displaying the filtered springs and their stack combination with force required for clamp and unclampconditions enables the designer to make a quick decision on the best disc spring stack to optimize the spindle and tool clamp cylinder design [21].

When we compare this method, we have recognized the computational system generates the list of feasible spring stack combinations instantly. Usually, it takes a couple of weeks in manual mode. Since this system eliminates the manual calculation process, it helps the designers to do more design iterations to select the best-optimized design and focus on the other design process. Also, we identified the computational system as a spool proof method that does not allow human error, which is commonly unavoidable during the long calculation of spring stack selection in the conventional method. 


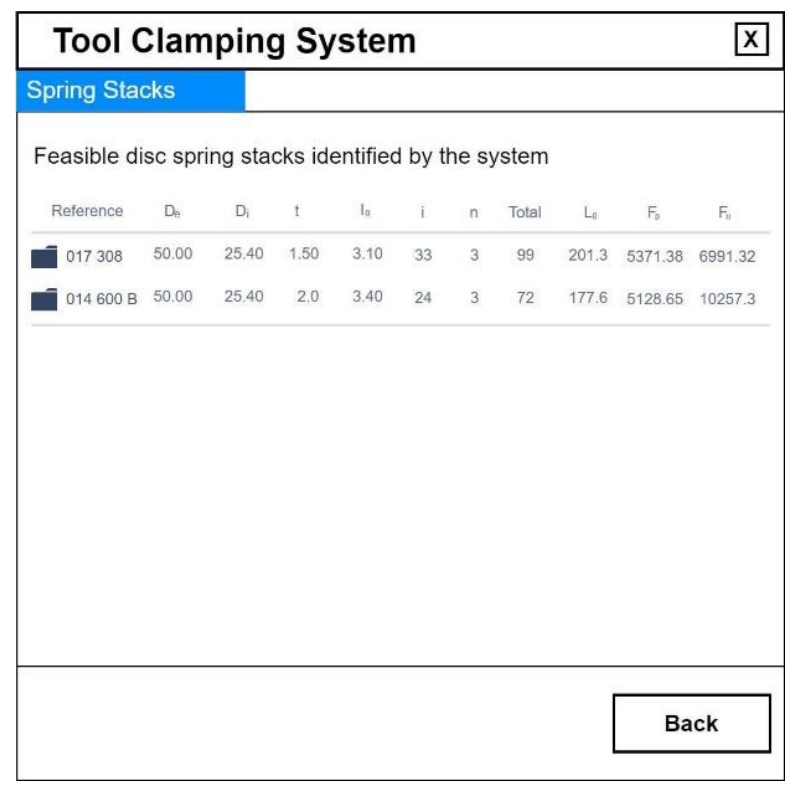

Figure 7. Reference system design to display results

There are some advantages of application system for the design of the spindle tool clamping mechanism such as:

a. Instant solution by the computation system reduces the research hours and improve productivity.

b. Error-free calculation method

c. Modularity in design parameters

d. A robust method to achieve an optimized solution

e. One-time application development

f. The scalable system allows us to add or modify design criteria.

While the limitation of this study is this system is only focusing on disc spring stack selection in the tool clamping system design.

\section{CONCLUSION}

We are proposing this system to machine tool designers since the computer-oriented approach is the robust method to design and optimize the tool clamping system. The development is one time, and the usability of the system is a lifetime. The development cost is also meager since the availability of open-source licenses. Implementing such a system in the R\&D department can remarkably increase the productivity rate and help the core engineers focus on further research in a tool clamping system. The main intention of the paper is that this system should be useful to machine tool industries to improve the tool clamping design process.

\section{REFERENCES}

[1] E. Abele, Y. Altintas, and C. Brecher, "Machine tool spindle units," CIRP annals, vol. 59, no. 2, pp. 781-802, 2010, doi: 10.1016/j.cirp.2010.05.002.

[2] M. C'isar, I. Kuric, N. C ubon 'ova', and M. Kandera, "Design of the clamping system for the cnc machine tool," in MATEC Web of Conferences, vol. 137, 2017, p. 01003, doi: 10.1051/matecconf/201713701003.

[3] D. Zhu, F. Ding, H. Liu, S. Zhao, and G. Liu, "Mechanical property analysis of disc spring," Journal of the Brazilian Society of Mechanical Sciences and Engineering, vol. 40, p. 230, 2018, doi: 10.1007/s40430-018-1152-2.

[4] S. Smith, T. Jacobs, and J. Halley, "The effect of drawbar force on metal removal rate in milling," CIRP Annals, vol. 48, no. 1, pp. 293-296, 1999, doi: 10.1016/S0007-8506(07)63187-4.

[5] Y. Chen, C. Chiu, and Y. Cheng, "Dynamic analysis of disc spring effects on the contact pressure of the colletspindle interface in a high-speed spindle system," Proceedings of the Institution of Mechanical Engineers, Part C: Journal of Mechanical Engineering Science, vol. 223, no. 5, pp. 1191-1201, 2009, doi: 10.1243/09544062JMES1329.

[6] F. Ahmed, L. F. Capretz, S. Bouktif, and P. Campbell, "Soft skills and software development: A reflection from the software industry," International Journal of Information Processing and Management(IJIPM), vol. 4, no. 3, pp. 171-191, 2013. 
[7] B. R. Konsynski, J. E. Kottemann, J. F. Nunamaker Jr, and J. W. Stott, "Plexsys-84: An integrated de- velopment environment for information systems," Journal of Management Information Systems, vol. 1, no. 3, pp. 64-104, 1984, doi: 10.1080/07421222.1984.11517710.

[8] C. L. Borgman, D. O. Case, and C. T. Meadow, "The design and evaluation of a front-end user interface for energy researchers," Journal of the American Society for Information Science, vol. 40, no. 2, pp. 99-109, 1989, doi: 10.1002/(SICI)1097-4571(198903)40:2<99::AID-ASI4>3.0.CO;2-7.

[9] B. W. Kernighan, Programming and Programming Languages, Princeton University Press, 2017, pp. 67-86. [Online]. Available: http://www.jstor.org/stable/j.ctvc775pg.12

[10] K. E. Iverson, A programming language, John Wiley \& Sons, Inc.: USA, 1962, pp. 345-351.

[11] W. S. Davis and D. C. Yen, The information system consultant's handbook: Systems analysis and design, CRC press, 2019.

[12] "Hollow taper interface with flange contact surface - Part 1: Shanks - Dimensions," International Organization for Standardization, Standard, 2001.

[13] B. Bossmanns and J. F. Tu, "Conceptual design of machine tool interfaces for high-speed machining," Journal of Manufacturing Processes, vol. 4, no. 1, pp. 16-27, 2002, doi: 10.1016/S1526-6125(02)70130-8.

[14] K. Yang, S. Guan, and C. Wang, "The design \& calculation for hydraulic cylinder of workpiece hydraulic clamping system of a special cnc machine for guide disc," Procedia Engineering, vol. 16, pp. 418-422, 2011, doi: 10.1016/j.proeng.2011.08.1105.

[15] E. Mechtly, The international system of units: physical constants and conversion factors, Scientific and Technical Information Division, National Aeronautics and, 1969, vol. 7012.

[16] M. W. Blasgen, "Database systems," Science, vol. 215, no. 4534, pp. 869-872, 1982, doi: $10.1126 /$ science.215.4534.869.

[17] “Design of conical disc springs," Deutsches Institut für Normung, Berlin, Germany, Standard, Jan. 1992.

[18] E. Fromm and W. Kleiner, Disc Springs handy for use, Adolf Schnorr GmbH, Hela Werbung, Heilbronn, art.-No. $901721 / 7.97$.

[19] J. Kleinberg and E. Tardos, Algorithm design, Pearson Education India, 2006.

[20] R. J. Jacob, "User interface," Encyclopedia of Computer Science, John Wiley and Sons Ltd.: GBR, 2003, pp. $1821-1826$.

[21] S.-L. Jeng, L.-G. Chen, and W.-H. Chieng, “Analysis of minimum clamping force," International Journal of machine tools and manufacture, vol. 35, no. 9, pp. 1213-1224, 1995, doi: 10.1016/0890-6955(94)00113-X.

\section{BIOGRAPHIES OF AUTHORS}
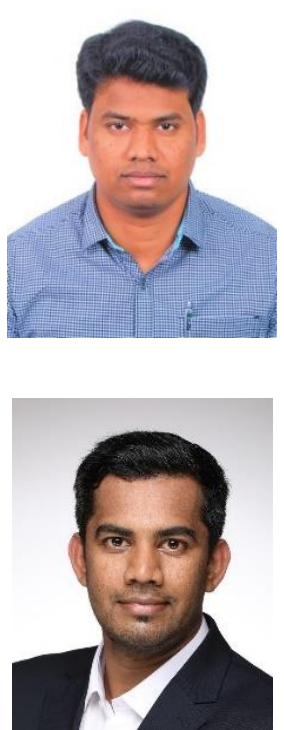

Parthiban Kannan is a Digital transformation expert who works in multiple domains, including Machine Learning, Extended Reality, CAD \& CAE automation, Graphics automation, Application development (Desktop, Web \& Mobile), Machine Design, and Finite Element Analysis. His educational background is Artificial Intelligence and Machine Learning in the postgraduate program and Mechanical Engineering in the undergraduate program. His career activities' significant contribution is the Research and Development of Machine tools and Switch-gear products. He gives solutions to the core Mechanical and Electromechanical problems through his IT skills, and you may learn more about him at www.parthibankannan.com.

Ragul Ramanathan is a mechanical engineer with a focus on research and development. He has received a M.Sc. (Materials technology) from Technical University Bergakademie Freiberg, Germany, and B. Tech (Mechanical engineering) from Amrita Vishwa Vidyapeetham University, India. His area of expertise is Machine design, Machine tool - Horizontal and Vertical Turing center, Plastic injection molding machines, Additive Manufacturing - Binder jetting, Industrial automation, CAD, Finite element analysis, Lean Six Sigma, and Industry 4.0. 